\title{
Unpacking the Relationship Between Value and Empowering Behaviours of Leaders
}

\author{
Yi Liu, Hong Li* \\ School of Economics and Management, University of Chinese Academy of Sciences, Beijing, China
}

\author{
Email address: \\ Yi.liu.sx@gmail.com (Yi Liu), lihong@ucas.ac.cn (Hong Li) \\ ${ }^{*}$ Corresponding author
}

\section{To cite this article:}

Yi Liu, Hong Li. Unpacking the Relationship Between Value and Empowering Behaviours of Leaders. Psychology and Behavioral Sciences. Vol. 6, No. 5, 2017, pp. 79-89. doi: 10.11648/j.pbs.20170605.12

Received: August 20,2017; Accepted: August 31, 2017; Published: September 22, 2017

\begin{abstract}
For improving product quality and shifting from manufacturing to a service based economy, many organizations are undergoing organization structure transformation from hierarchy to decentralization in order to facing the increasingly fierce global competition. In the new and more flat form of organization structure, the practice of empowerment is regarded as an effective mechanism benefiting both employees and organizations and has attracted lots of researchers' attention. This paper aims to investigate the relationship between the value of founders in startups and their empowerment behaviors. This study generated a comprehensive empowerment behavior questionnaire with 9 dimensions. Based on context analysis on the interviews of startup founders, their values were coded according to the definition system of the value studies by Schwartz. And the primary relations between empowerment behavior and personal value is explored. The results showed that the growth and anxiety-free part of a circular motivational continuum with 19 values are more positively related to empowerment behavior and the other part, self-protection and anxiety avoidance is less positively related to their empowerment behavior. Future research is also discussed in the paper.
\end{abstract}

Keywords: Empowering Behavior, Value, Entrepreneurship

\section{Introduction}

In order to cope with the rapidly changing external environment, the organizational structure could be transformed from the traditional centralized management to the flat and decentralized mode. Empowering leadership as a new style of leadership has drawn lots of attention of leadership scholars. The concept is also in line with the increasingly fierce external competition environment and the organizational structure reform from the traditional hierarchy with high-level control to flat and decentralized autonomy management requirements. Within the organizations, the overall level of knowledge of employees is improving, and the requirements of self-employment and self-efficacy are also improved. Several studies have shown that empowerment behaviors of leaders could enhance the employee's self-efficacy and work autonomy [1], which could increase employees' power perception [2] and then improve their intrinsic motivation and finally benefit individual organization commitment [3], the individual creativity [4] and organization performance [5].

Though antecedents of psychological empowerment are gradually clear, some researchers indicate that managers of middle level are unwilling to empower their subordinates, for delegation and empowering are seen as the power diminishment [6], and signal that their positions are unnecessary [7].

Values, from the philosophical point of view, are the beliefs that people have about things, and the fundamental and systematical views of what is right and what is wrong to do and think [8]. From a psychological point of view, values are the way people behave, and the choice of target means. From the organizational behavioral perspective, values are the basis for understanding a person's attitude and personality [9]. Value is the common concerned issue in humanities, social sciences, ethics, pedagogy, anthropology and other disciplines. In a broad sense, values reflect a person's interests, hobbies, choices, obligations and responsibilities and other aspects of the content. In a narrow sense, the value is a way of evaluation 
of things and a selection criterion, which exists in everyone's deep mind. And the predictive of Schwartz's value theory on behaviors has been verified [10-12].

This paper trying to know investigate values influence the empowering willingness of leaders, conducted a pilot inductive study via interviews to give an insight and try to put forward a reliable hypothesis to future studies. Related definitions are explained as bellows to remove confuse and make it easy to navigate.

\section{Theory Background}

\subsection{Empowering Behaviors}

\subsubsection{Definition}

"Empowerment" is a word evolved from "empower", which contains two parts of meaning. The prefix "em" means that aroused or enable somebody or something stay in some kind of situation. The broad meaning of "power" is the authority. And the "power" in the organization management are ability, capacity, and energy, momentum and drive.

Though the concept of empowerment is highly related to leaders' power alienation, followers' job enrichment and participative management, the core of empowerment aims to increasing followers' self-efficacy and their powerful sense to solving problems and making decisions. Opinions on the core of empowerment have experienced about 30 years' evolution. From the 80 s of 20 centuries, empowerment has become a widely-used concept in the organization behavior theory and enterprise management practice. In these times, empowerment has been seen as a set of decision-making awards with the decision-making power shifting from leaders to followers.

In the late of $80 \mathrm{~s}$, Conger and Kanungo [1] started the research on empowerment from the perspective of psychology. They defined empowerment as the process of follower's endeavor to improve their performance and self-efficacy. Based on Conger's research, Thomas and Velthouse [2] described the motivation intrigued by empowerment as the intrinsic task motivation, the inner motivation to work. They explained the meaning of power: first, from the legal aspect power could be officially authorized and the empower process also could be officially delegated by leaders to followers; second, power also includes the individuals' capacity to complete and achieve something; besides, the meaning of power includes energy so the empowerment process includes the energizing process. The last two levels of power meaning give a more vivid explanation of empowerment process, not only the authority delegation but also containing a dynamic and interaction with employees storing their energy and building their self-confidence and self-efficacy.

Zimmerman [13] separated psychological empowering from organizational empowering, which have developed to two research columns [14]. Researches of organizational empowering mostly based on the macro social structure view to investigating that how should organizations, leaders, and managers act to intrigue staves' intrinsic motivation from the management perspective. However, researchers of psychology empowering mostly based on micro personal psychological state, to investigate the anecdote, outcomes of psychological state, moderating or mediating effect.

\subsubsection{Dimensions}

The empowering behavior of leaders are parts of organizational empowering, includes authority delegation, accountability, self-directed decision making, information sharing, skill development, coaching [15], leading by example [16], process control, and outcome control [17].

Konczak [15] developed the Leader Empowerment Behavior Questionnaire (LEBQ), which includes six dimensions, delegation of authority, accountability, self-directed decision making, information sharing, skill development and coaching for innovation performance. And they also found that these six dimensions of leaders' behavior have a positive relation to the employees' empowerment perception, by empirical studies. In addition to the information sharing dimension with two items, other five dimensions all contain three items, a total of 17 items.

Arnold [16] had studied empowerment behavior in the team context and developed ELQ (Empowering Leadership Questionnaire), which has been widely used to measure leaders' empowering behaviors, which includes five dimensions, coaching, information, leading by example, showing concern and interacting with the team, and participative decision making. This questionnaire includes 38 items in total and could be tested both on the team level and individual level [16].

In recent years, several Chinese scholars studied the content of empowerment behavior in the Chinese context. Wang [17] found the different dimension of empowerment leadership behaviors through two empirical studies, which were identified as individual development, process control, delegation authority, outcome control, participation in decision making and coaching for work. Though the meaning of dimensions of Wang are similar and related to scales developed by western scholars, for example, the individual development support dimension is similar to Amold's ELQ concerning dimension, and the participation in decision making dimensions is similar to Konczak's LEBQ authority delegation, and also the coaching and participation dimensions, in the Chinese context, employees are more focused on the individual development support from their leaders, including individual ability improvement, career planning, and training or other further study opportunities. In Wang's [17] finding, two dimensions of process control and outcome control are conforming to Tsui's [18] study, who claimed that manager's behavior in China requires abilities of articulation vision and monitoring operation. He explained that the control situation is highly related to the thousands of years of Confucian culture, the Chinese traditional culture, with the core value of hierarchy and obedience, which still have an extraordinary influence on Chinese behavior and of course the leaders' and employees'. But the process control and outcome control is relaxed broad control focusing on the internalized task commitment and motivation, instead of not 
strict control with clear reward and punish. In addition to the cultural perspective, Wang [17] gave another explanation to the necessity of control for Chinese leaders' empowerment behavior. For most industries and the country are still in the primary development period, rules and regulation are not completely perfect built.

Above three scales all expressed the core meaning of empowerment behavior, delegation, self-decision and responsible, personal emotion caring, and coaching or leading behavior, but some distinctions still exist. The shortcoming of the scale of Konczak [15] is not fully emphasized participated decision and made a relatively narrow definition of information sharing, only on high-quality results and customer needs information. For employees, self-directed decision making is just focused on the tasks they are responsible for, not involved their new ideas and opinions into the leader' decision. The scale of Arnold [16] with more details and specific information to define the empowerment behavior, highly emphasized the coaching and showing concern/ interacting with the team, which two dimensions include 21 items in total. And comparing with the scale of Konczak [15], he released a new dimension, leading by example dimension, which aims to explain that leader's working and behavior would become a high standard for subordinates to learn and follow. Besides, Arnold [16] enlarged the content of information sharing, including the purpose of company policy and strategy, and the reasons for leader's decision. The scale of Wang [17] released a new dimension based on the Chinese cultural, process and outcome control, but less emphasis on the coaching and encouraging behaviors.

Analyzing these three above widely used empowerment leader behavior questionnaires, we could find that even though the numbers of factors and the structures are different, several questions of different scale have a common meaning. Based on the overlapping and the unique parts, empowerment behaviors are concluded into 9 dimension, which are self-development support, emotional connection, justice and praise, information sharing, process and outcome control, self-decision and responsibility, participated decision, helping and coaching, and leading by example, with detail explanation in the below Table 1 .

Table 1. Empowerment Behaviors with 9 dimensions.

\begin{tabular}{ll}
\hline Factors & Explanations \\
\hline Self-development support & Concerning employee's personal career development, encouraging to learn and willing to provide resource on training \\
Emotional connections & Caring employee's personal emotion, encouraging and building their confident via unformal chatting and talk. \\
Justice and praise & Treating everyone fairly, rewards and promote justly. \\
Information sharing & Sharing work-related information, company strategy, policy information, and willing to explain leader's decision. \\
Process and outcome control & Setting goals and check process regularly, evaluating work performance. \\
Self-decision and responsibility & Encouraging employees to take responsibility of their own task and making decisions by their own. \\
Participate decision & Encouraging employees to release new ideas, respect and willing to take these suggestions, and making decisions together. \\
Help/coaching & When employees encounter difficulties, giving suggestion and help, not intervention directly. \\
Leading by example & Working as hard as they can, and set as a good example as how they behave. \\
\hline
\end{tabular}

\subsection{Value}

\subsubsection{Definition}

Kluckhohn [19] defined that values are what is good, what is worth to do for individuals, which recognition could guide individual's behavioral patterns and decide the attitudes and behavior when people engaged in some activities. Values are not a single concept, but a multi-concept system, as a decision-making function. England [20] argues that managerial values determine their moral standards and that values influence the one's relationship with other organization members, also the manager's attitude towards decision-making and handling of work. The effect of value on individual behaviors is long-term, sustained and direct. Georel and Jones [21] defined values as an attitude that affects individual decision-making, which attitude will continue to influence the individual's perception of the surrounding environment and determine individual decisions and behaviors.

Values have multiple functions, and that the value not just limited to evaluation as perceived, but also have a binding function that binds the behavior of the individuals [9]. The restraint function of value, could play a normative role. This improvement on value knowledge is seen as a big step forward in advancing the progress of research on values and is therefore got general interests of value scholars.

\subsubsection{Dimensions}

Over the years, the study of values has attached many scholars' attention. Most acknowledged values scales are six category scale of Burke [22], Rokeach's Value Survey with 18 items within two types, and the most widely used Schwartz Value Survey with 57 items and 10 values.

The significant breakthrough of Rokeaeh's the Value Survey scale is that Rokeaeh uses a systematic perspective and presents a systematic theory of values, comparing with previous listing value scale. He classified these values into two categories, while the value of each type options is not isolated, with an internal logical relationship and a sequence according to the importance. But to rank 18 items is difficult as well as time-consuming, rating scales have been explored as an alternative measuring means to collect value data by Rokeach's value survey. Wellins [23] developed the LOV scale, a simplified version of the Rokeaeh's terminal value scale. It includes nine dimensions: a sense of belonging, excitement, warm relationships with others, self-fulfillment, 
being well respected, fun and enjoyment of life, security, self-respect, and a sense of accomplishment. The LOV scale evaluates these nine dimensions using the Likert seven-point scale, which is measured from very important from the very unimportant.

Considering from the central assumption of the value survey, most studies were employing that theory of basic values as discrete entities, while values are all grounded in one or more three universal requirements of human existence. Besides, it is necessary to partition the motivational continuum values into a well-defined conceptually distinct value, to capture more specific motivational differences on these continuums of values. Based on these kinds consideration, Schwartz [24] proposed a new refined theory of human values, with 19 values instead of the original 10 . He added the face dimension to measure the security and power to maintaining one's public image and avoiding humiliation, and humility dimension to measure one's recognition of insignificance in the larger scheme of things.

A limitation of short scales of values is that they maybe not represent all types of values and inadequate for research on particular issues. And the full Schwartz's 56 items have been tested and found stable across many countries, considering leader's value from the collective whole view could guarantee external validity. Comparing SVS, the PVQ-RR give more specific and details to evaluate personal values and provides an option to choose dimensions independently based on different studying topics. Besides, the three circle of value creates a macro view to analysis values from different perspectives, personal focus vs. social focus, and grow/ anxiety-free vs. self-protection/anxiety avoidance.

Based on the above reasons, this paper chooses PVQ-RR to investigate leaders' value and the relationship between their empowerment behavior and values.

\subsection{Theory Analysis}

It has been widely acknowledged that value is an important part of leadership system, which will lead leadership to choose a variety of acts, but this broad concept still attracted lots of scholars' attention to make it specific. Conger and Kanungo [1] pointed out that moral leader depends on a high level of values in their leadership behavior. Harari [25] and Rothstein [26] focused on the value characteristics transformational leadership and its value system. Jun Liu believed that the CEO's value may enhance or weaken the behavior of its followers, which depends on the follower's attitude and reaction about how the CEO's value is consistent with their transformational behavior. He studied CEO's value in two value dimensions, self-transcendence, and self-enhancement. Leaders' with higher self-enhancement value paid more attention to their own rights and happiness and leaders with higher self-transcendence value concerned more about the interests and happiness of others. Leadership behavior and values are closely linked, and leadership value through leadership behavior to influence subordinate behavior and their performance. Leadership values determine the leadership's feelings about different individuals and organization, helping leaders to choose between right and wrong, morality and immorality. At the same time, leaders may prefer subordinates with similar values and exclude subordinates with different values.

In the paper, personal values are one of the antecedents of leader's behavior, which could influence leader's behavior consciously or unconsciously, and of course, have an influence on the organization culture and subordinate's value and behavior, ultimately have an influence on the organization performance. Self-development support indicates that leaders are willing to provide resource and opportunities to training subordinates skill and broaden their knowledge, tolerance their mistakes, and care about their personal career development from internal promotion or external opportunities. From the value perspective, subordinates are in-group members, and the people leaders' have to spend lots of time to deal with, so people emphasize more on benevolence-caring (devote to the welfare of in-group members) could provide more resource to support subordinates training and their welfare.

Conformity-impersonal value is to avoid upsetting or harming surrounding people, not annoying anyone, irritating people. This value factor with benevolence-caring and humility constitute the basic reason for leaders to care about employees' emotional need and courage, and build their confidence.

Universalism-concern value refers to commitment to equal status, justice opportunities, and protection weak and vulnerable members. From this dimension, leader highly values this justice and equality have more chance to evaluate employees' work equally and provide equally promotion and praise, then view them equal with leaders themselves, respect their self-career development, autonomy on tasks and working methods, and right to know company strategy and policy.

In the humility value dimension, it is important that people not just draw attention to themselves, also pay attention to people they are dealing with. So, when leaders are emphasizing humility, they could draw attention to their subordinates. Besides this part of the meaning, humility is also emphasized that people's recognition of their insignificance in a larger scheme, being humble. This part of meaning in the management practice could explain as that employees' decision and opinion could be more accurate, effective in leaders' eyes. This could be a basic assumption to the leader that they should release more authority, letting employees making their own decision, taking their own responsibility, and give him more suggestion.

From the self-direct thought and action factors, people believe that the autonomy, and freedom of opinion, action is important to themselves, they could also accept the autonomy and freedom to complete tasks with their own ideas and own original opinions, and have more possible to delegate authority to employees, more freedom to choose and working independently, and expect their creative and original ideas.

The universalism-tolerance value is to accept and understand those people who are different and promote the harmony and peace among teams and accept disagreements of 
others. When leaders could understand people, who is disagree with him, it is possible for him to encourage team members' opinion and suggestion, then absorb these new ideas into their decision or decide with his subordinates.

Power-dominance and power-resource are the controlling on people or material, social resources. People with the value higher on these two dimensions enjoys more on dominate people, high status, and fortune power, the sense of influential, who have less opportunity to delegate their authority to subordinates which could be seen as losing control, losing the sense of existence and couldn't realize the importance of their own. In the same time, these negative senses could raise their anxiety of uncertainty, who may see others' development as a threat to themselves and provide less training, information sharing, and teaching behavior.

Conformity-rules is to comply with authority, formal and informal rules, and laws. The more important of conformity rules for a person, the more compromises he has, and he more likely to lose his own original opinion and creativity, then become more reliable on others. In the management practice, employees' working content, working methods would be seen as a small part of the large system and process has to follow. Leaders more emphasized on this dimension, more likely to control process and outcome regularly, and less likely to release autonomy to employees to encourage their own working methods and steps.

On the whole, leaders with higher values of self-enhancement are more inclined to control the working process and outcome, and less likely to delegate authority to employees and sharing working related information. Leaders with higher values of openness to change are more intended to support individual development, release authority, and give autonomy to making their own decision and sharing more company strategy and policy information. Leaders' with higher values of self-transcendence care more about the employee from the working and personal emotions, build personal emotional connections with them, and treat them equally, and encourage different opinions, have more participated decisions, and more guidance and coaching leading behaviors. Leaders' with higher values of conservation, more likely emphasize the working procedure and organization regulations, with less autonomy delegation and self-decision opportunities for employees.

\section{Method}

\subsection{Procedure}

Based on grounded theory, it is possible to induce theory and relations from original material and interviews. To explore the relationship between entrepreneur personal value with their empowering behavior, this paper holds four interviews based on exists measurements of value and empowering behavior.

Interviews are one of the independent qualitative research material resources. And researchers could combine interviews and literature analysis and participant-observation to investigate. Interviews allow researchers to obtain subjects' experience and interpretation. The advantage of interviews of qualitative research, researchers have an opportunity to understand things they can't see and touch, instead of the interpretive based on their own experience; have an opportunity to find unexpected outcomes in the interview conversation occasionally.

Questions could be structured before interviews, and could be placed or added in the interview process as semi structure question, or guided and formulated in unstructured or conversational interviews. Though there are mature empowering behavior scales, leaders' management behavior could cover serval dimension at the same time. But there' not much intersection between personal value dimensions gave by Schwartz. So, in this paper, the empowering behavior part was designed as unstructured and conversational interviews, and the value part was designed as a semi-structured interview.

Participants were asked to describe their actual management practice and their feeling about those value dimensions. Leaders' behavior and values are classified, to give a qualitative sense about what they did and how they feel. But at the same time, the behaviors and values could be evaluated as for how much they are empowering, and how much they are emphasizing this value factor. There were four entrepreneurs selected as interviewees. Interviews held by the online instant communication application, WeChat. The interview form of online call is similar to the telephone interview with more advantages. First, considering the busy working situation of entrepreneurs, online calling has great variability to adjust the interviewing time based on everyone's schedule with little traveling and waiting time. Besides, internet calling is convenient for the interviewer to check on transgressions when asking questions and remove the effect of interviewer characteristics on interviewees.

After interviews, according to the concept of empowering behavior, management practice was coded and categorized. To present a more specific relation between personal value and empowering behavior, the level of these two concepts was scored and transformed into quantitative numbers.

\subsection{Sample}

Start-ups are widely known as classical organizations have to face a high level of uncertainty in the market competition, and high risks of being merged or bankrupt. These uncertainties could be translated into low efficacy feeling of employees in the start-ups [1]. After identifying that the organization is in the context of powerlessness, managers should try to take empowerment strategies and tactics to remove the negative sense of powerlessness and building their self-efficacy. But considering the Chinese unique management style, paternalistic leadership, which authority lead dimension includes behaviors like unwilling to delegate authority, information inclusive, strict controlling, maintain dignity in front of employees which are opposite the content of empowerment behavior.

Participants were selected as follows: he is the core team member (owner and runner with risk) with authority to decide 
the company strategy and policy; the company, he is fighting for, has more than 20 employees; the company has been found more than one year. Based on these rules, I found four respondents who have enough time to participant interviews. Because some participants claimed that company's news and reports are strictly controlled, they are unwilling to show both their real name and the name of their company. So, in this paper, respondents are numbered by English capital letter, A, B, C, and D. A brief introduction of those interviewees and their company as below.

A. One intelligence parking hardware company, found in 2015 with more than 50 employees now.

B. One education training company, found in 2014 with more than 20 employees in this period.

C. One intelligence deep mind software company, found in 2014 with more than 30 employees.

D. One Apple maintenance service provider, found in 2012 with more than 50 employees in this period.

\section{Analysis and Results}

\subsection{Interview Analysis}

\subsubsection{Empowering Behavior}

Four participants empowering behavior would be explained and evaluated respectively as below:

A. Participant A believed that, employee training is necessary because he could find that the new comers cannot handle the tasks directly he delivered. So, to improve their efficiency, the leader organized training every Friday, which topic suggested by employees, with a very wide scope technology or business. Personal emotional communication is frequent, for his team is small enough and we all know each other very well. Besides they have team building activities once a month, and it is convenience to communication both work and personal life in these activities. Subordinates weekly plan were made by themselves and they have full autonomy to decide how they would like to finish their task without leader's control. But considering the decision efficiency, action autonomy is mainly emphasized in the middle-level management team, not the bottom-level employees, and the final goal is always under leaders' control. When the subordinates did something, wrong or had some confusion about their work, the leader just gave suggestions and found the right person who could really help subordinates. In the company decision process, most decisions were made by the whole management team and everyone' opinion is as important as his. Besides, the leader also works as hardest as he could, not only because this company is his career, but to become a good example is also important to motive subordinates.

Overall, the level of empowerment is moderate in this company. Regular training, self-decision within the scope of authority, though autonomy is mostly held by the middle-level managers and subordinate. Training is to ensure the smooth progress of work, not individual career development.

B. In this interviewee B's eyes, those people found a company with him is the core member of the team, and the new comers with specific functions, accounting, coding, marketing mainly focus on their responsibility and no need to have more personal emotional connections. In the management team, members are equal when making decisions, all have voice right and information knowing right. But considering the working efficiency, functional new comers were being assigned tasks and tried to complete in time. Because when recruiting these new comers, their abilities to take responsibility most work are acquired, there is not too much need to training and coaching. There are exceptions. If most management team members highly valued one employee, it is possible to give him a chance to have external training. Mistakes could be accepted if time allowed, or in the uncontrollable context, but the people frequently making mistakes have the risk to be fired. In total, the level empowerment behavior in this company is low. Participation decision is only happened in the management team, haven't become the atmosphere of the whole company. Individual development is not emphasized and the subordinates are not equally concerned with the management team.

C. The thing makes the interviewee $\mathrm{C}$ proud of, is that there's no trust cost in his company. The team members, his classmates, or his fellow from the hometown, have followed him for about three years. Technique skills and management experience of the members are all helped and taught by himself in the early stage. So, in this developing stage, the leader could totally trust his management team and support their individual development, even if they could leave and start another maintenance service competing with him. The word he mentioned most frequently is sincere, as his management principle and his value to do business. Based on the trust, subordinates have full autonomy to complete their tasks with a little target control from the leader. A big difference with other interviews is that he views every one of his company is equal to have voice right and autonomy, self-development opportunity. $\mathrm{He}$ is pleased to sharing company strategy or technical information with his employees, which behavior is viewed as the curiosity, creativity and motivated with bright personal future. Decisions about the company strategy, external partners are mainly made by himself, with an open mind to accept other members' critical opinion or suggestions. New comers are trained in the apprenticeship system, whose mistake firstly have been taken by the teacher and then the apprentice. And mistakes were seen as the unavoidable growth booster to help employees become a master faster.

Overall, the level of empowerment behavior is high, with high evaluation of individual development, personal emotion concerning, self-decision autonomy, frequent information sharing, and voice behavior and participate decision, little process and outcome control. Besides, the interviewee also pays attention to members' everyday work and gave equal praise, and giving support to his subordinates as much as he could.

D. This interviewee is fully involved in this start-up, everything meaningful is must related to the achievement of 
his goals. Decisions were made based on every team members' opinion, even those are a critical suggestion, and willing explain reasons why he made that decision to comfort subordinates' emotion and information needs. When communicating with his project manager, target and deadline is the only requirement that he delivered. This means that his project manager has full autonomy to decide the content and work intensity of this task. In the personal development perspective, individual technique development is helpful to the team efficiency and company performance, and it is important to motive subordinate's subjective initiative. So, he supported lots of external training opportunities to technique staffs. When subordinates have questions, if guide or suggestion on methodology is able to solve the problem, he would not to help give specific solutions. Besides, he was trying to become the working hardest one in the company to become an example full of positive energy.

In total, the level of empowerment behavior is high in this intelligence deep mind service company. New comers all have a supervisor to guide his work and external training is always available and encouraging to improve their working skills and self-development. Tasks completing methodology and working intensity was by members, and the leader just set a final goal and deadline to finish with a little control. The personal emotion was concerned and different opinions were encouraged in the company. Besides, subordinates were equally evaluated and praised both in the work and the personal status.

Table 2. Examples of empowering behavior rated as high and low.

High empowering behavior
A: Solving problems one by one is time and energy wasting. I will collect common issues and give
a training once a week. In general, I only controlled the outcome and time. Managers have
autonomy to decide how to finish tasks.

B: I think we have equal status when solving problems and setting goals, for the core team. For employees, evaluated promising by our core teams, have opportunities to sign up an external training program. For small and recurring issues, employees have full autonomy to make decisions by themselves.

C: This period, we have more than 30 people. Benefit for the small scale, I still have time and energy to ask employees' opinion when I making decisions and explaining my thought and company strategies, of course, build personal emotion relations. Generally, I delegate tasks to related project manager and have a little process control. In my company, every new employee has a supervisor to guide and help. When I was asked, specific solution or methodology are all possible, that depends. Leading by myself is very important, which is the foundation of the trust.

Self-motivated is the core difference between human and robots or animals. I hope them could develop their skill and abilities.

$\mathrm{D}$ : The core competitive of my company is the zero-trust cost. I fully trust my employees, without any afraid of making company clients private, stealing mobile phones or computers, and financial cheating. Privately, the team members are all my good friends with close relationships, always playing mahjong and having dinner together. And they won't hesitate to point my mistakes. I am very happy when my employee has questions, which means that they are concentrating on the tasks, and company growing,. I am not the most talented one in my company, for everyone is the specialist in his area. The status I am trying to set is honest and sincere.

\subsubsection{Value}

Four participants value would be analyzed and evaluated respectively as below.

Interviewee A strongly emphasized on four factors, self-direction action, power-dominance, benevolence-caring, and universalism-concern and extremely emphasized on two factors, achievement and face. Enjoyment of life is considered not important in this rough fighting stage. He believes that before the age of 45 to make his company successful, enjoying life and have fun in this period is wasting life. Besides, maintaining dignity and a glorious image is extremely important to him. The importance of conformity rule, self-autonomy-thought is dependent on the role of he would play. In the middle management level, it is important to give own opinions and show creativity, but when people facing amount of regular task should be complete in a limit time in the bottom level of the company, obeying rules and improving efficiency is much more
Low empowering behavior

A: For middle and bottom staffs, the executive efficiency is the most important, which goes against to autonomy. But for managers or core team members, autonomy and their own ideas are necessary. B: For new comers, they were viewed as employees to finish specific tasks, without too much autonomy and personal emotional relations. Our company was too small, without enough resource to wait for employee developing their skills. Usually, they were fully qualified when recruited

C: Staffs could make their own decision in the autonomy scope. Though I will not control process directly, my project manager will be the charge of it, task delegation, process and outcome control.

D: In general, I make most decision indecently, includes target setting, operation plans, and strategy negotiation. important.

Interviewee B has strongly emphasized on five factors, self-direction thought/action, achievement, power-resource, conformity rule and highly emphasized on two factor, power-dominance, benevolence-caring. He is willing to help family, friends, and others as much as he could and always concern other emotion and fare ware conditions. Besides, he also mentioned that he hates to lead by others without his own opinion, but people admiring him or having a high voice right is a great experience and feeling which will make him feel good. But he also mentioned that the public image question is depends on the situation. If he actually did wrong or behave not properly, it is fine to point out his mistake in the public. Conformity to authority also depends on the adverse consequences. If the consequence has a large negative influence on his life, he would give his opinions and ideas to follow advice from authority ones.

Interviewee $\mathrm{C}$ has strongly emphasized on the five 
factors, stimulation, conformity-interpersonal, benevolence - dependability, universalism - concern / nature, and extremely emphasized on four factors, self-direction thought/action, humility, and benevolence-caring. $\mathrm{He}$ believed that the autonomy and freedom of opinion and actions are people's basic requirement. On the humanity dimension, he believes that he is not perfect and not the one who works hardest in the company. Interviewee $\mathrm{C}$ would glad to know people's different ideas, which means his friends or colleagues are creative and motivated with bright future. And it is very important to help people who dear to him, giving support and show his concern. Even to the weak and vulnerable ones he met, he always shows his sympathy and helped them, though some disable were cheating to some extent. About the power-dominance and power-resource dimension, he mentioned that money or resource is not important to him, the feeling he would enjoy is the process of working hard with people he trusts and makes something different, makes his employees and customers satisfied. Protecting his public image is unnecessary and being criticized in front of his friends or family wouldn't make him awkward or ashamed. The sense of security of personal or society was not important in his opinion because after a long time unsettled and tough working experience he is strong enough to give himself security. And about the rules, he believes that startups are people who have a mission to challenge unreasonable rules, a system in the society, but not the laws.
Interviewee D has a strong emphasis on three factors, humility, universalism-concern, universalism-tolerance, and highly emphasized on two factors, self-direction thought/action, and achievement. He believes that everyone has different specializing talent in his own field, he is just a half of expert in his field, and it is important to absorb different ideas and suggestion from kinds of people. In the same time, he highly emphasized the autonomy of self-direction thought and action, because he believes the autonomy and creativity are the key factors to distinguish the people from mechanical machines. So, when he was making decisions, though opinions from others were encouraged and considerable, he would mainly assist his own opinion with a little adjustment based on others suggestions. As a leader of a start-up company, there's no life for him, of course, the entrainment activities. The only goal he is trying to achieve is to make his idea and service successful and have a great influence on people and the society. Based on this belief, the dominance of people, and power of money and resource is totally not important. But he also mentioned that to some extend the power of resource could be helping him to achieve his goal faster and more efficiently. Public image or security of person is also not important, only if these could help his business. From the conformity-rules, he believes that rules are no need to strictly obey because rules themselves have unreasonable part, could be broken and improved.

Table 3. Examples of personal value rated as high and low.

\begin{tabular}{l} 
High value \\
\hline A: I am aiming to realize my financial freedom before 45 and develop my career \\
as large in this stage. I wish I could have freedom and ability to act independently \\
as possible. Maintaining my image and avoiding humiliation is very important for \\
me.
\end{tabular}

B: Personal thought and action freedom are very important for myself because I don't like to be led by the nose. But, the feeling of leading others is not bad. Everyone wants to become the leader with higher voice power, with resource delegation rights and higher choosing opportunity to complete tasks as I want. When in conflicts happens with authority on important issues, I usually will combine with them. Because I believe that they are the specialist with more reasonable judgments. For my family and friends, I am ready to help them as much as I could. Rules are necessary for the society and every organization.

C: Personal autonomy and motivation make humans different from robots, with their own judgments, decisions, and critical thinking. Even when facing authority, I also encourage others to have their own independent opinion. I am not the most successful person in my company, but I am the most diligent one, to being the example and inspiring others working hard as I am. Everyone should develop their skills to complete tasks indecently. So, I don't like others rely on me, just trust me. Protecting weak and vulnerable is necessary.

D: I like people full of curiosity and creativity, and encourage employees to put forward their own opinions, so do I. Traditional culture is the treasure of our country. We all need to conform and pass it to the next generation. In my opinion, entrepreneurs are the people trying to break rules and create a new and better world. Parents' every decision and action is starts from love. So, I could understand what they did and said, though I know sometimes they are wrong. For people who have helped me, I will keep in mind and help them selfless even many years have passed.

\section{Low value}

A: I am still in the struggle stage of my life, so not highly valued pleasure and gratification. I respect traditional custom, but I maybe not abide these rules. I never think about the security sense of the environment and the society.

B: I only pursue excitement in games, in the virtual world; but in the reality, I prefer steady and less fluctuate life style.

I don't have too much requirement on the face and I will be appreciated if someone could point out that even if in the public and in the front of my friends. Comparing with the traditional rules and custom, being the true self is much more important. I could not be the best one in the world, so I have to accept others' merits and learn from them. For the disable with kind hearts, I am willing to help them, but for those disable make money and use others' sympathy, I hate them.

C: People who start a new company don't have a life anymore, let alone joyful and leisure. I am not the people who focus on money and power, I just want to do something different. Being the CEO, dressing neatly, caring about team members' emotional needs, all for sake of this mission. I care about voice rights, authority, face, environment security, only if these affairs are helpful for my mission.

D: I am not that kind of people open to everything new. For example, I am not willing to try new restaurants, and new food actively, unless my friend recommended. I was an ambitious man two years ago, opened more than 10 shops in different cities. But now, I just enjoy the process and want to perfect tasks in my hand. For people who could adjust their inner state, it is easy to feel happy, joyful and safety. 


\subsection{Relation Analysis}

Based on the leaders' explanation of their value, their value emphasis on each item could be revealed by the numbers from "-1" (opposite to his value), "0" (it doesn't matter to him), "1" (relatively important), "2" (important), "3" (extremely important). To increase measure validity, the author and other three external organization behavior field specialists were asked to assess values independently based on the same code. After three internal assess validity indexes test, $R_{w g}$, ICC (1), and ICC (2), the average scores of each item are shown in the below Table 4 .

Table 4. Results of interviewee'value and the variation.

\begin{tabular}{|c|c|c|c|c|c|c|}
\hline Factors & & $\mathbf{A}$ & B & $\mathbf{C}$ & D & Variation \\
\hline \multirow{3}{*}{ Openness to change } & Self-direction-thought & 1.25 & 2.50 & 2.50 & 2.75 & 1.00 \\
\hline & Self-direction-action & 1.75 & 2.25 & 2.75 & 3.0 & 1.40 \\
\hline & Stimulation & -0.50 & 1.25 & 0 & 0.25 & -0.29 \\
\hline \multirow{4}{*}{ Self-enhancement } & Hedonism & -0.25 & 1.25 & -0.5 & 0.5 & -0.36 \\
\hline & Achievement & 2.75 & 2.25 & 0.5 & 0.25 & 0.06 \\
\hline & Power-dominance & 1.75 & 2.50 & 0 & 0.5 & -0.45 \\
\hline & Power-resource & 2.25 & 2.00 & -0.25 & 1.00 & 0.10 \\
\hline \multirow{5}{*}{ Conservation } & Security-personal & 1.25 & 1.50 & -0.75 & -0.5 & -0.44 \\
\hline & Security-societal & -0.25 & 1.25 & -0.25 & -0.75 & -0.63 \\
\hline & Tradition & 1.50 & 1.25 & 1.75 & 2.50 & 1.5 \\
\hline & Conformity-rules & 2.50 & 2.50 & 0.50 & 1.00 & -0.25 \\
\hline & Conformity-interpersonal & 1.25 & 1.25 & 1.50 & 1.50 & 2.00 \\
\hline \multirow{5}{*}{ Self-transcendence } & Humility & 1.25 & 2.00 & 2.50 & 1.75 & 0.80 \\
\hline & Benevolence-dependability & 1.00 & 1.50 & 1.75 & 2.50 & 1.17 \\
\hline & Benevolence-caring & 1.50 & 2.50 & 2.50 & 2.75 & 1.00 \\
\hline & Universalism-nature & 1.25 & 1.75 & 2.25 & 3.00 & 1.29 \\
\hline & Universalism-tolerance & 2.25 & 1.50 & 2.50 & 2.50 & 2.38 \\
\hline Average & & 1.45 & 1.79 & 1.09 & 1.47 & 0.63 \\
\hline
\end{tabular}

Interviewee A has a moderate level of empowerment behavior; the second interviewee has a low level of empowerment behavior; interviewee $\mathrm{C}$ and $\mathrm{D}$ have high level of empowerment behavior. Interviewees with a high level of empowerment behavior has higher score in the self-transcendence part and lower score in the conservation part, and much higher score in the openness to change part than the other two interviewees. The first two interviewees, A and $\mathrm{B}$, with moderate and low level of empowerment behavior, have relative higher score in the self-enhancement part and the conservation part.

In order to show the difference of their values more clearly, the qualitative description can be further transformed into quantitative indicators through the formula (1), to draw the final conclusion. To show the variation between the high level and low level, trying to add the score of $\mathrm{C}$ and $\mathrm{D}$, half of $\mathrm{A}$, and then minus the score of $\mathrm{B}$ after min-max normalization, as showed in Table 4, it will be clear to know the value difference between those four leaders based on their behavior. For the empowerment behavior of interviewee B is low, when calculating the final index, explaining the difference value among them, his value scores increased by " -1 " to explain that his value is negative to the empowering behavior. Because the moderate level of interviewee A, his value could be increased by 0.5 , to show his positive but not fully empowering behavior.

Variation $=$ Score $_{\text {high }}+0.5 *$ Score $_{\text {moderate }}-$ Score $_{\text {low }}$

The value variation score could have been seen in the last column of Table 4. Now it is clear to see that, self-direction thought, self-direction action, tradition, conformity-interpersonal and all factors of self-transcendence are higher valued by leaders have a higher level of empowerment behavior. And factors of self-enhancement and conservation, except tradition and conformity interpersonal, are less emphasized by a higher level of empowerment leaders. In Schwartz's value circle, self-transcendence and openness to change could be classified as grow and anxiety-free part in the outermost circle, to express people growth and self-expansion and motivating people when they are free of anxiety. Self-enhancement and conservation are classified as self-protection and anxiety-avoidance part in the outermost circle, to express people are more likely to protect themselves against anxiety and threat.

\section{Conclusion}

Based on the measurement and analysis of empowerment behavior and the situation of start-ups, this paper investigated the relationship between entrepreneurs' empowerment behavior and their values.

This paper discussed the difference of three widely acknowledged empowerment behavior questionnaires and generated a more comprehensive scale with nine dimensions of empowerment behaviors. Then explored the relationship between entrepreneurs' value and their empowerment behavior based on theoretical analysis and empirical analysis, generated reasonable hypothesis and conducted a pilot survey 
via four interviews of four entrepreneurs.

According to Schwartz's PVQ-RR value survey and an integration empowerment behavior scale with the generated 9 dimensions, we put forward and verified the theoretical hypothesis about their relationships: leader's empowerment behavior is positively related to leader's value of growth and anxiety free, negatively related to their self-protection and anxiety avoidance value part, based on the value circle model of Schwartz [24].

For the resource limitation, the number of interviewees is quite limited. To some extent, the limited sample size errors from sampling could bring several errors from following variables, the demographic characters of interviewees (age, education background, gender, and race etc.), the industries, growth stages etc. In the next wave interviews and quantitative research, demographic variables could be controlled.

Besides, two interviewees have mentioned that their caring behavior is frequent at this stage is mainly because there are not too many employees in the company, and they still have spare energy and time to build a personal connection and sharing information with others. Leadership style is in a dynamic changing process based on the outside environment and the life stage of the company. So, in the future studies, it is necessary to investigate entrepreneurs' value and their empowerment behavior at different company life stages.

Based on social identity theory [27] and value congruence [28] researches, leaders may have stronger willingness to empowering employees who have much more similar values and excluding employees with different values. In the future, scholars could try to investigate how the value dissimilarity among leader and subordinates influence the leader's empowering behavior, subordinates' psychology empowerment and performance.

\section{References}

[1] Conger J A, Kanungo R N. "The empowerment process: Integrating theory and practice," J. Academy of Management Review, 1988, 3, 471

[2] Thomas K W, Velthouse B A. "Cognitive elements of empowerment: An "interpretive" model of intrinsic task motivation," J. Academy of Management Review, 1990, 4,666

[3] Spreitzer G M. "Social structural characteristics of psychological empowerment," J. Academy of Management Journal, 1996, 2, 483

[4] Sun L-Y, Pan W, Chow I H S. "The role of supervisor political skill in mentoring: Dual motivational perspectives," J. Journal of Organizational Behavior, 2014, 2, 213

[5] Chen G, Kirkman B L, Kanfer R, et al. "A multilevel study of leadership, empowerment, and performance in teams," J. Journal of Applied Psychology, 2007, 2, 331

[6] Klein J A. "Why supervisors resist employee involvement," J. Harvard Business Review, 1984

[7] Antonakis J, Atwater L. "Leader distance: A review and a proposed theory," J. The Leadership Quarterly, 2002, 6, 673
[8] Schwartz S H. "Universals in the content and structure of values: Theoretical advances and empirical tests in 20 countries," J. Advances in experimental social psychology, 1992, 1

[9] Rokeach M. "The nature of human values,"M. Free press, 1973

[10] Schwartz S H, Butenko T. "Values and behavior: Validating the refined value theory in Russia," J. European Journal of Social Psychology, 2014, 7, 799

[11] Liñán F, Kurczewska A. "Why are some individuals willing to pursue opportunities and others aren't? The role of individual values," J. Research Handbook on Entrepreneurial Opportunities: Reopening the Debate, 2017, 263

[12] Kirkley W W. "Entrepreneurial behaviour: the role of values," J. International Journal of Entrepreneurial Behavior \& Research, 2016, 3, 290

[13] Perkins D D, Zimmerman M A. "Empowerment theory, research, and application," J. American journal of community psychology, 1995, 5, 569

[14] Spreitzer G. "Giving peace a chance: Organizational leadership, empowerment, and peace," J. Journal of Organizational Behavior, 2007, 8, 1077

[15] Konczak L J, Stelly D J, Trusty M L. "Defining and measuring empowering leader behaviors: Development of an upward feedback instrument," J. Educational and Psychological Measurement, 2000, 2, 301

[16] Arnold J A, Arad S, Rhoades J A, et al. "The empowering leadership questionnaire: The construction and validation of a new scale for measuring leader behaviors," J. Journal of Organizational Behavior, 2000, 249

[17] Walumbwa F O, Wang P, Wang H, et al. "Psychological processes linking authentic leadership to follower behaviors (Retracted article. See vol. 25, pg. 1071, 2014),” J. Leadership Quarterly, 2010,5,901

[18] Tsui A S, Wang H, Xin K, et al. "Let a thousand flowers bloom": Variation of leadership styles among Chinese CEOs," J. Organizational Dynamics, 2004, 1, 5

[19] Parsons T, Shils E A, Allport G W, et al. "Some fundamental categories of the theory of action: A general statement," J. Toward a general theory of action, 1951, 3

[20] England R. "A program for the solution of boundary value problems for systems of ordinary differential equations," R. 1976,

[21] Georgel J M, Jones G R. "Experiencing work: Values, attitudes, and moods," J. Human Relations, 1997, 4, 393

[22] Burke W. "Leadership as empowering others," J. Executive power, 1986, 51

[23] Wellins R S. "Empowered teams: Creating self-directed work groups that improve quality, productivity, and participation," M. ERIC, 1991

[24] Schwartz S H, Cieciuch J, Vecchione M, et al. "Refining the theory of basic individual values," J. Journal of Personality and Social Psychology, 2012, 4, 663

[25] Harari O. "Stop empowering your people," J. Management review, 1997, 2, 48 
[26] Rothstein L R. "The empowerment effort that came undone," J. The Journal of Product Innovation Management, 1995, 12, 347

[27] Ashforth B E, Schinoff B S, Rogers K M. "I identify with her," "I identify with him": Unpacking the dynamics of personal identification in organizations," J. Academy of Management Review, 2016, 1, 28
[28] Hoffman B J, Bynum B H, Piccolo R F, et al. "Person-organization value congruence: How transformational leaders influence work group effectiveness," J. Academy of Management Journal, 2011, 4, 779 